\title{
Asymptotic response of friction stir welded joint under cyclic loading
}

\author{
Imane Elmeguenni \\ Mechanical research center CRM, Constantine, Algeria \\ imaneelmeguenni@gmail.com, bttps:/ / orcid.org/0000-0001-7272-9843
}

\begin{abstract}
Fatigue takes a place more and more important in the design of structures, it remains a key point in the mechanical dimensioning of structures. The Friction Stir Welding (FSW) process is regarded today as the most promising alternative to traditional joining methods. It ranks among the most recent assembly processes and is considered a new technique for the $21 \mathrm{st}$ century. Indeed, if the FSW welding process has several advantages, it introduces very strong microstructure heterogeneities in the welded joints.

This leads to heterogeneous mechanical behavior in each of the constituent zones. some important efforts have been deployed in industry as well as in research laboratories to understand the behavior of welded joints by the FSW process. There are many questions about the behavior of these areas.

This study led to the characterization and understanding of the fatigue behavior of a 2024-T351 structure welded by the FSW process. It presents in a numerical work which aims to help determine the asymptotic response of each zone constituting the 2024-T351 joint welded by FSW subjected to a cyclic loading and to fully understand the behavior of these zones.

To carry out an analysis and a simulation under cyclic loading, our choice fell on the use of the direct cyclic method. Numerical simulation of crack propagation was performed using the extended finite element method (XFEM).

This research consists in the implementation of the XFEM in fatigue in a multiscale model XFEM / direct cyclic.

The numerical results consist in highlighting the heterogeneities in the mechanical behavior of the welded joint and in evaluating the impact of the FSW process on the failure of these FSW zones.
\end{abstract}

KEYwORDS. Direct Cyclic; FSW; XFEM; Fatigue; Asymptotic response.

\section{OPEN ACCESS}

Citation: Elmeguenni, I., Asymptotic response of friction stir welded joint under cyclic loading, Frattura ed Integrità Strutturale, 58 (2021) 202-210.

Received: 14.06 .2021

Accepted: 13.08 .2021

Published: 01.10.2021

Copyright: (C) 2021 This is an open access article under the terms of the CC-BY 4.0, which permits unrestricted use, distribution, and reproduction in any medium, provided the original author and source are credited.

\section{INTRODUCTION}

$\mathrm{F}$ riction stir welding (FSW) is a new solid-state welding, method developed by TWI in the 1990s, offering several advantages over conventional welding methods [1, 2] FSW uses a rotating and traversing non consumable tool to generate frictional heat and cause mechanical deformation at the joint [4]. 
Friction stir welding uses the principle of convection of mechanical energy, produced by the pressure and rotation of the tool, into thermal energy by friction of the latter with the parts to be assembled. The heat generated generates localized transformations where the material changes from an elasto-viscoplastic behaviour with high mechanical resistance to a viscoplastic behavior with low resistance, favoring the formation of the junction [22]. The FSW process, shown schematically in Fig.. 1, During the welding process, heat is generated due to the friction between the tool and the workpiece, as well as due to the severe plastic deformation of the material [5].

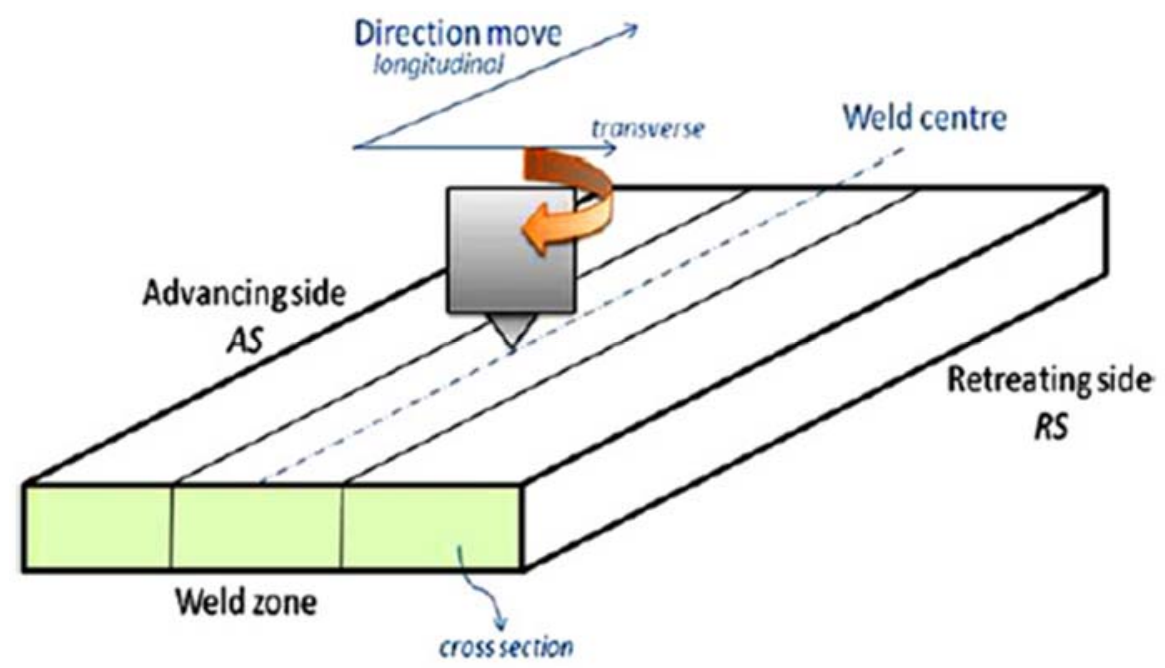

Figure 1: Geometry of FSW process, also indicating the tool transverse direction [6].

A welded joint is made only from the base metals of the assembled parts and does not require any filler metal [4].

The weld created by this process is not symmetrical about the parting line. The side where the two velocity vectors (translation and rotation) are in the same direction is called "advancing side" (AS). The one where these two vectors are opposite is called a "retreating side" (RS) (Fig. 1) [2].

During welding, a thermal and mechanical gradient is introduced, leading to a microstructure gradient within and around the weld [1]. The FSW community unanimously agrees on the number and naming of the macroscopic areas that make up the FSW welded joint. In general, the welded joint has four zones: the core, the thermomechanically affected zone (ZATM), the thermally affected zone (ZAT) and the base metal (MB). So the FSW welding has a very heterogeneous microstructure along the joint, the shape of the bead, the grain size and the size of the areas constituting the joint (Fig.2).

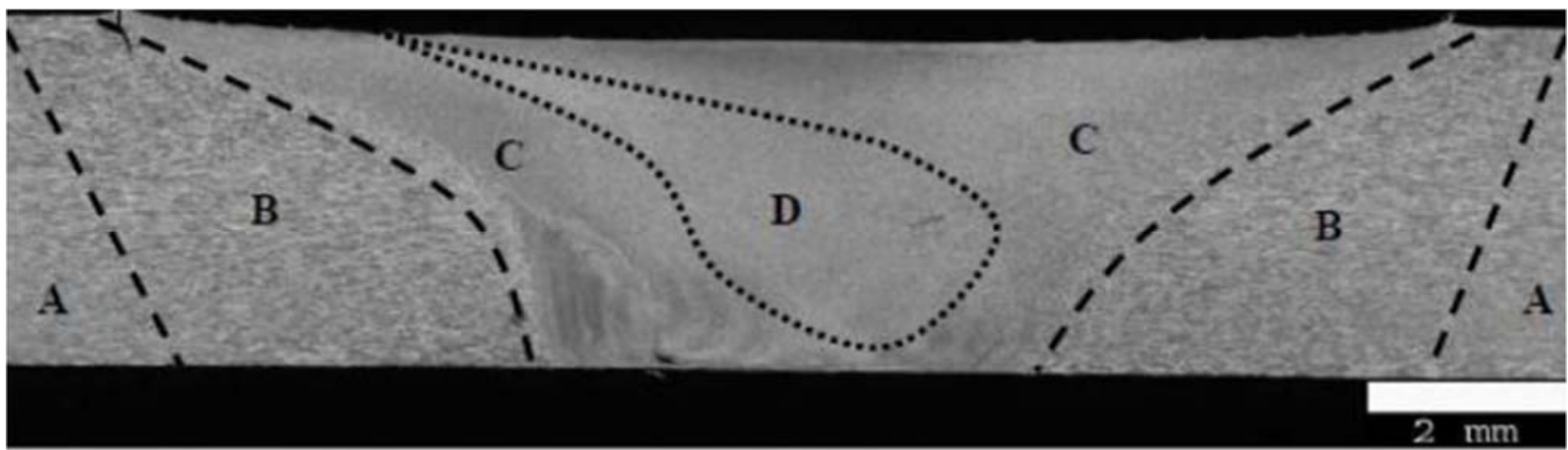

Figure 2: Macrographic section of a weld bead from AA7020 showing four distinct areas: (A) base metal, (B) heat affected area, (C) thermo-mechanically affected area and (D) nugget.

These heterogeneities introduced by FSW welding make it difficult to study the mechanical behavior of these joints this study constitutes an element of response and of the comprehension of the behavior of the joint 2024-T351 welded by FSW aiming at the numerical development of this joint and the implementation of the method of the extended finite elements (XFEM) in cyclic loading. 
For broadening and improve understanding the joints FSW, it is necessary to clarify the local fatigue behaviour of different areas of the FSW joints. The fatigue crack propagation of FSW is known to be concerned by the both microstructures around the welded zone [3].

\section{NUMERICAL APPROACH AND DEVELOPED MODEL}

$\mathrm{D}$ espite a good number of publications on the FSW process, the characterization and numerical analysis of the harmfulness of the defects in the different areas of these joints remains limited.

This work is in addition to the various research studies that deal with the mechanical behavior of aluminum alloys welded by the FSW process and strongly contributes to numerically understanding the local fatigue behavior of the 2024T351 joint.

The XFEM method has been used in order to successfully simulate the phenomenon of crack propagation in friction stir welded joint, without forgetting to take into account the plasticity at the crack tip, and to perform analysis and simulation under cyclic loading, we chose to use the direct cyclic method.

So therefore our work consists in the establishment of the XFEM in fatigue in a multi-scale model XFEM / Direct cyclic. The model coupled will be the most powerful and efficient tool for solving various problems in the fatigue behavior.

The XFEM was introduced by Moës and al. in 1999. The idea of XFEM consists in enriching the basis of the classical finite element method by a step function along the crack line to take into consideration the discontinuity of the displacement field across the crack and by some non-smooth functions representing the asymptotic displacement around the crack tip. The latter enrichment is the so-called singular enrichment [7], It allows enables automatic mesh generation with each new step of the crack growth $[8,9]$.

Till now XFEM has been most widely applied in solving crack problems, including fatigue crack propagation, and threedimensional crack propagation, XFEM has also been implemented to solve plasticity problems [10]. Many works have been achieved in order to explore the capabilities of the XFEM and improve its accuracy as in $[7,9,10,11,16,17,18,19,20,21]$.
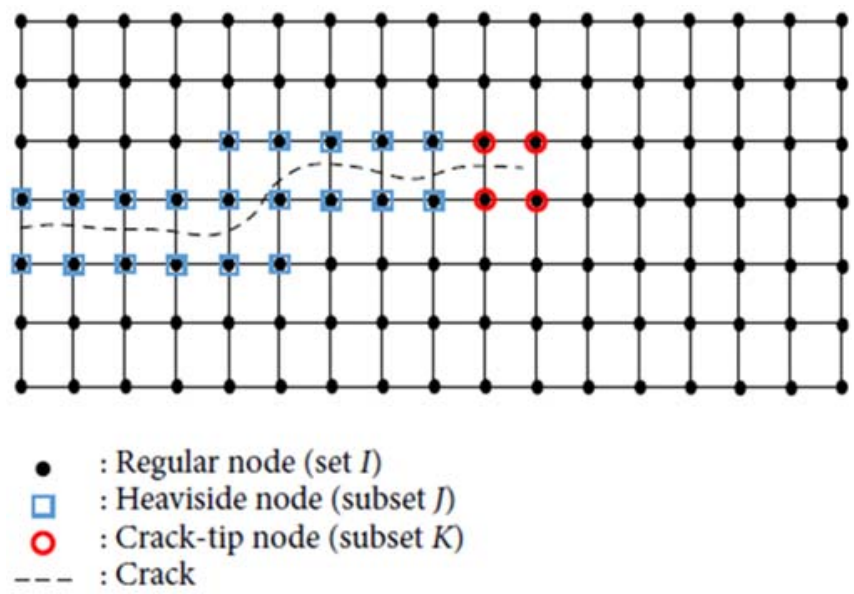

Figure 3: 2D finite element mesh of a cracked body [11].

\section{Presentation of the Direct CyClic Method}

7 he study and the numerical characterization of the mechanical behavior of a structure is based on the determination of the stabilized response of the structure subjected to cyclic loading. However, this asymptotic response remains difficult to determine by conventional simulation techniques, in particular because of the necessary computation times.

It then makes it possible to construct the mechanical response of the studied structure, loading increment by loading increment, then cycle after cycle until a possible stabilized cycle. At each increment, the calculation codes generally use an iterative scheme of the Newton-Raphson type to construct the solution of the problem [15].

An iteration of the direct cyclic method includes 4 stages main: 
- The global step: which makes it possible to search the kinematically and statically admissible fields at all times of the cycle by supposing known the field of plastic strains and internal variables at all times of the cycle.

- The local step: which allows, from the solutions of the global step, to search for fields that verify the law of behavior.

- The periodicity of the solutions which is imposed by a reinitialization of the plastic strains and the internal variables at the beginning of the cycle from the values obtained at the end of the cycle.

- The convergence condition which makes it possible to stop the iterative process checks the periodicity of the plastic strain fields and the internal variables at the end of the local step as well as the static admissibility of the stresses at the end of the local step.

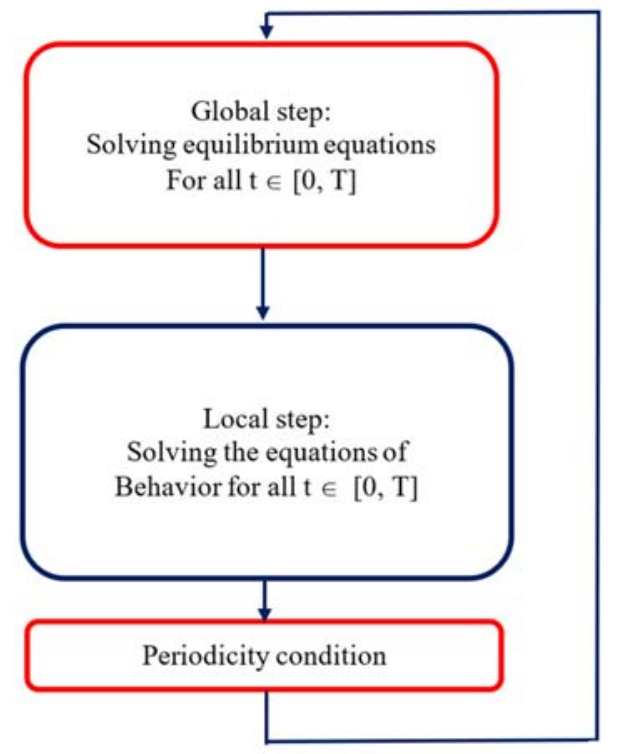

Figure 4: General principle of the direct cyclic method [12].

\section{APPLICATION OF THE METHOD TO THE CALCULATIONS OF JOINT FSW 2024-T351}

F our distinct materials are defined for the different zones; Base Material (MB) - Heat Affected Zone (HAZ) -ThermoMechanically Affected Zone (TMAZ) and Nugget $(\mathrm{N})$ within the developed model, so the constants are taken as follows:

Elastic party ; the mechanical properties of the welded joint 2024 T351 have been determined, the young's modulus and the Poisson's ratio are the same for all the zones, the hardening modulus and the exponent (n) vary along the welding zones (Tab. 1).

Elasto plastic ; stresses-strains have been described for all zones (Tab. 2), and without forgetting we take into account the mixing temperature of $2024-\mathrm{T} 351 \mathrm{~T}=550^{\circ} \mathrm{C}[23]$.

\begin{tabular}{lcccc}
\hline FSW regimes & NZ & TMAZ & HAZ & PZ \\
Young's modulus & 68 & 68 & 68 & 68 \\
(GPa) & & & & 0.33 \\
Poisson's ratio & 0.33 & 0.33 & 448 & 370 \\
Yield stress (MPa) & 350 & 272 & 719 & 770 \\
Hardening constant & - & 800 & 0.05546 & 0.086 \\
Hardening exponent & - & 0.1266 & 167 & 132 \\
Hardness (Hv1) & 142 & 118 & -20 & 0 \\
Residual stress (MPa) & -41 & 95 & & 0.33 \\
\hline
\end{tabular}

Table 1: Material properties of FSW zones [14]. 


\begin{tabular}{rlcccccc}
\hline PZ & \multicolumn{2}{c}{ HA } & \multicolumn{2}{c}{ TMA } & & NZ \\
& & \multicolumn{2}{c}{ Z } & \multicolumn{2}{c}{ Z } & \\
\hline Strain & Stress & Strain & Stress & Strain & Stress & Strain & Stress \\
0.0003 & 20 & 0.0004 & 25 & 0.0007 & 50.34 & 0.00044 & 30.43 \\
0.0006 & 40 & 0.0006 & 35 & 0.00123 & 75.86 & 0.0008 & 51.30 \\
0.0009 & 45 & 0.0010 & 58 & 0.0016 & 106.9 & 0.0012 & 69.56 \\
0.0014 & 90 & 0.00126 & 83 & 0.0020 & 131.03 & 0.0015 & 91.30 \\
0.0021 & 125 & 0.0015 & 95 & 0.0031 & 186.21 & 0.0021 & 130.43 \\
0.0034 & 220 & 0.0020 & 130 & 0.0045 & 268.96 & 0.0032 & 186.95 \\
0.0050 & 300 & 0.0028 & 175 & 0.0057 & 331.03 & 0.0043 & 286.96 \\
0.0058 & 320 & 0.00438 & 280 & & & 0.0055 & 331.91 \\
0.0084 & 440 & 0.00558 & 330 & & & & \\
0.0120 & 487 & 0.00898 & 480 & & & & \\
\end{tabular}

Table 2: Stress-strain data of FSW zones [14].

So, we formed numerically all the zones constituting the joint FSW 2024-T351 with the properties of each one ..., the model is already developed previously in our article [13] which treated a calculation XFEM under monotonic loading to determine the parameters of cracking of the joint 2024-T351.

In this work we wanted to highlight this approach on the same model in the cyclic regime, the same approach was adapted but with the cyclic numerical tests in order to achieve the asymptotic response of each zone in the welded joint $2024-\mathrm{T} 351$.

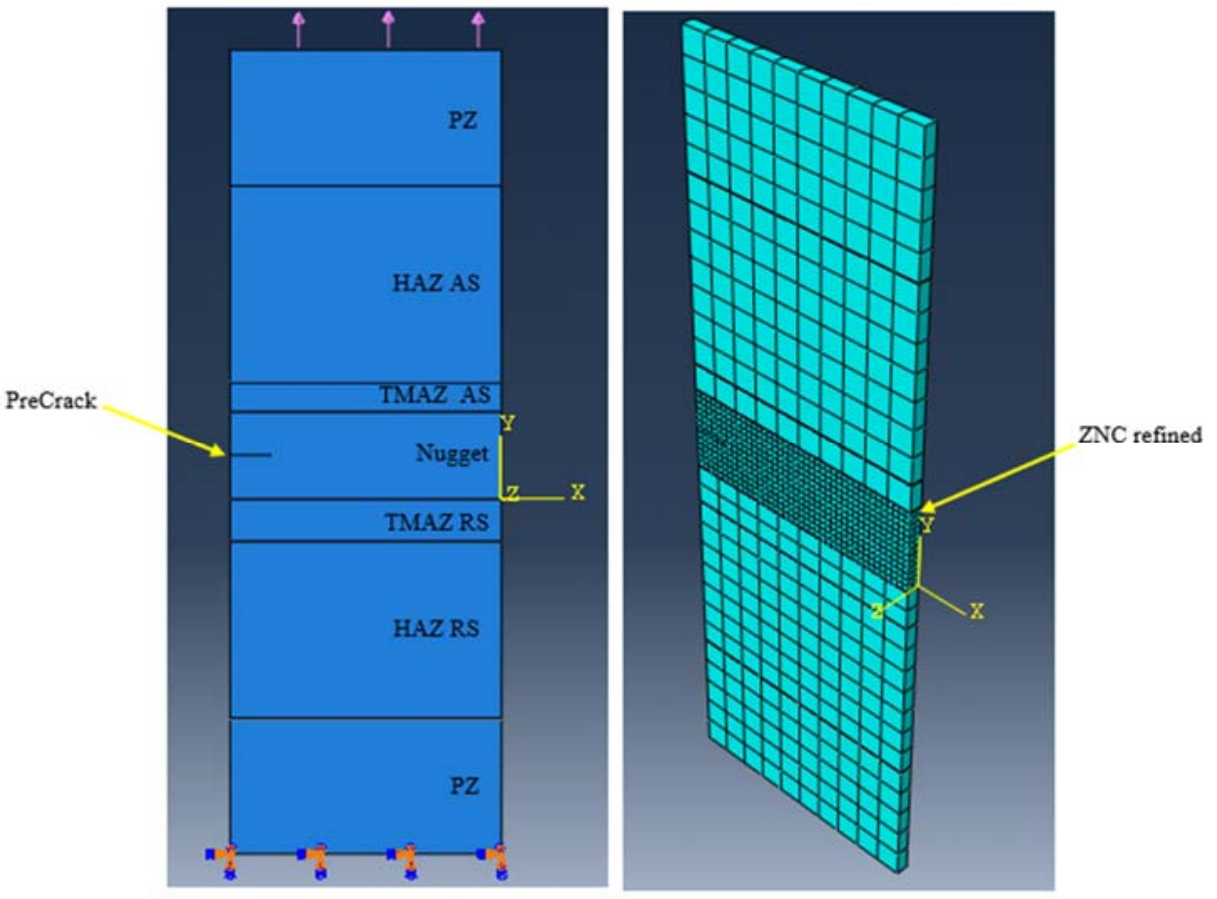

Figure 5: The model developed a) Geometry of the analyzed structure; b) Mesh of joint 2024-T351 [13].

The model FSW welded joint 3D using the calculation code by FE ABAQUS, developed on a rectangular thin plate precracked $\left(\mathrm{a}_{0}=3 \mathrm{~mm}\right)$ dimensions $60 \times 20 \times 1 \mathrm{~mm}$, so we choose a structured mesh (hexahedron) with volume elements at 8 (C3D8R) nodes without forgetting to finely mesh the cracked zone, of course the results are much more precise if the mesh of the the cracked area is finer.

Elasto-plastic crack-tip behavior must be written in order to take into account plasticity-induced loading history effects. Using the direct cyclic method, the stress-strain curves in each zone were determined. 
Fatigue tests in traction-traction were simulated in Abaqus / Standard under sinusoidal cyclic loading with imposed stress (Fig. 4). The maximum load applied to the specimen is $1 \mathrm{kN}$, the load ratio is $\mathrm{R}=\mathrm{F}_{\min } / \mathrm{F}_{\max }=0.1$ and the stress frequency is $20 \mathrm{~Hz}$. Fig. 5 illustrates the periodic amplitude imposed on ABAQUS.

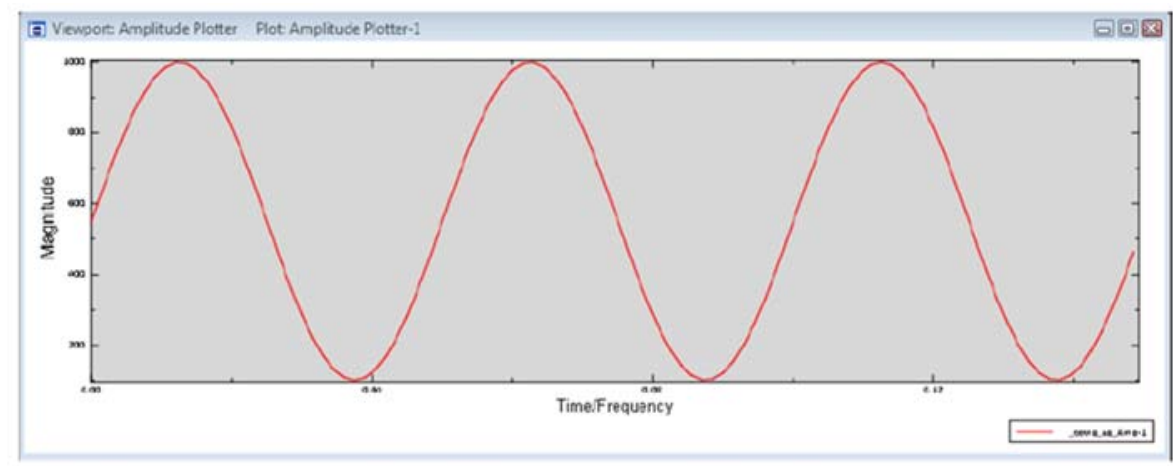

Figure 6: Amplitude applied during the fatigue test.

\section{STABILIZATION ANALYSIS AND NUMERICAL ILLUSTRATIONS (ASYMPTOTIC BEHAVIOR OF THE DIFFERENT ZONES)}

$\mathrm{F}$

ig. 6 illustrates the strain stress cycles $\left(\sigma_{22}\right.$ as a function of $\varepsilon_{22}$ ) at the nugget of the welded joint during a cyclic numerical test. The plot represents an element located very close to the crack point, which is why we see that the stress state changes from traction to compression during cycle depending on external loading.

Part (a) of the curve corresponds to the time required for the calculation code to reach the set point of the imposed loading. The calculation code requires one cycle (an average of 265 iterations) to perfectly reach the setpoint.

It is important to specify that for the simulated tests, the size of the time steps, size increments are 9.434e-4 for each cycle $(T=0.05)$ and the average number of iterations is at least 5 , therefore the calculation code repeats each iteration 53 times to complete the calculation and ensure satisfactory precision of the solution. Over the course of iterations, the solution is corrected until convergence.

It is noted that the cyclic mechanical behavior of the nugget of the welded joint in alloy 2024-T351 around the crack point has a ratchet effect (part b of the curve); strong variations of the variables of the model are observed, in particular with incipient plasticity.

Once the plastic field is well established the variations between the cycles are less important and the evolution of the internal variables tend towards a periodic state over a certain number of cycles, this is the accommodation. (Part c of the curve) up to about $90 \%$ of total life.

We note that the stabilization is very slow, the evolution of the stress-strain cycles during the iterations shows that we obtain a good approximation of the solution from 120 iterations with 50 Fourier terms as indicated in Fig. 7. The shape of the cycle is well represented, while the level of average deformations of the solution remains slightly estimated.

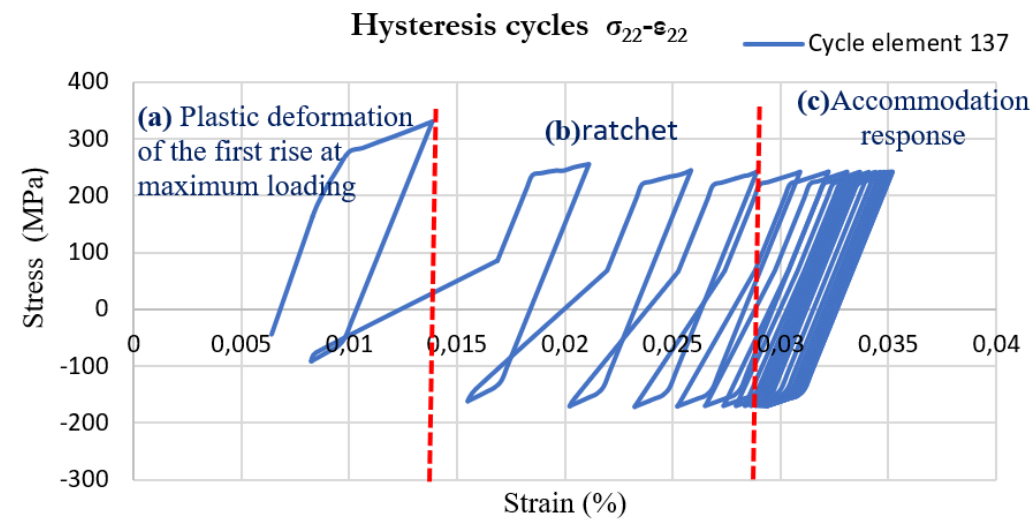

Figure 7 : Evolution of the stress-strain cycle of the nugget every 5 iterations, element 137. 

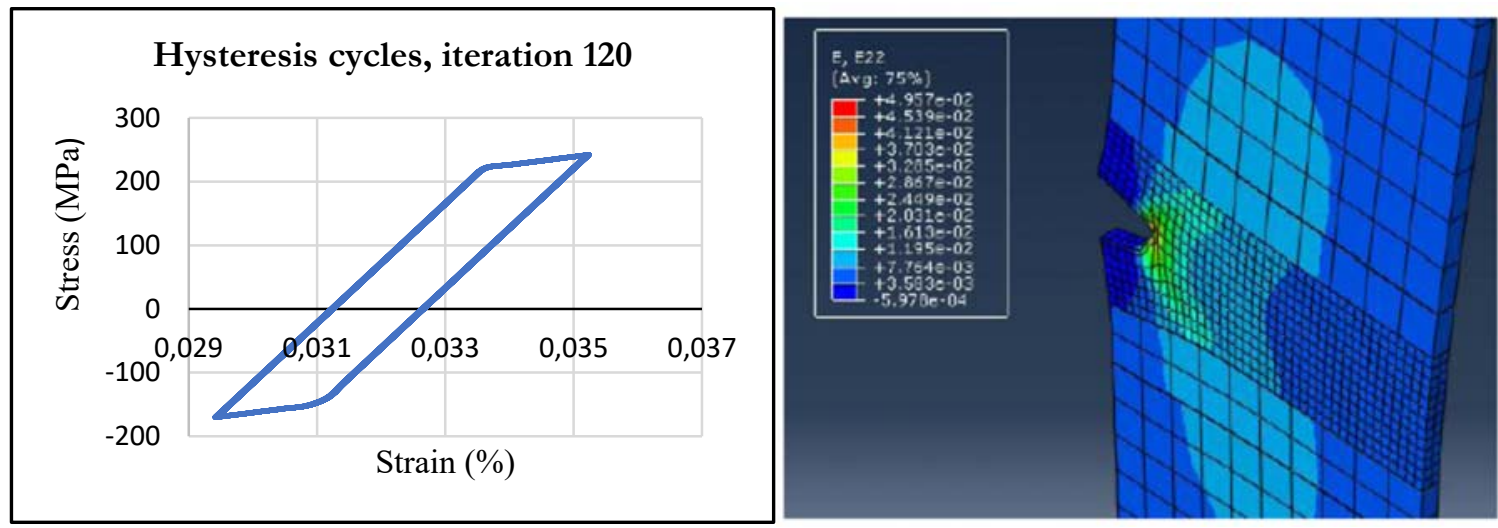

Figure 8: a) Stress-strain cycle obtained by DCM after 120 iterations. B) Deformation fields at the end of the cycle stabilized by DCM.
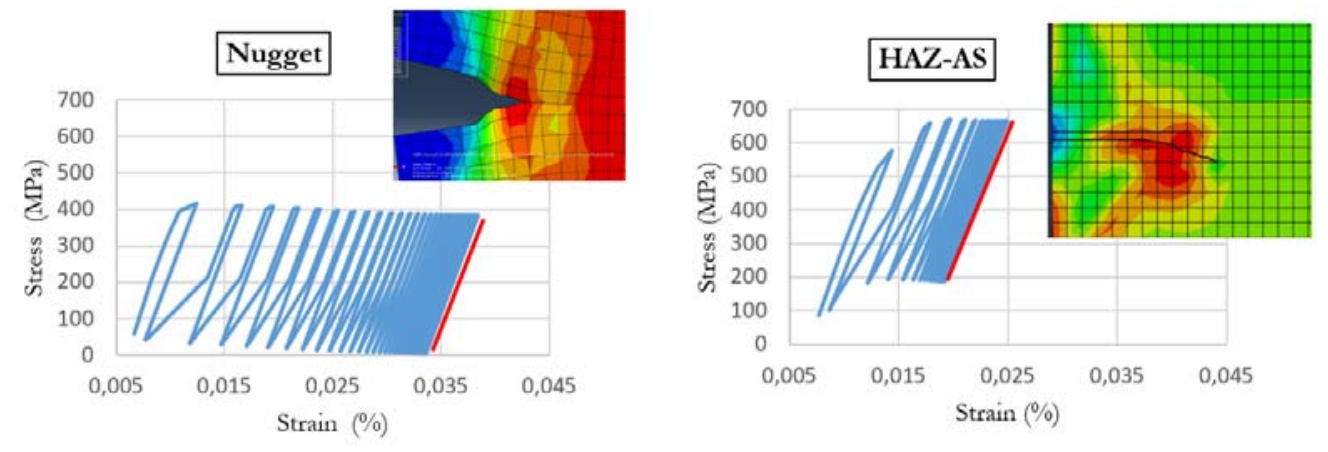

Cycle stabilized element 216

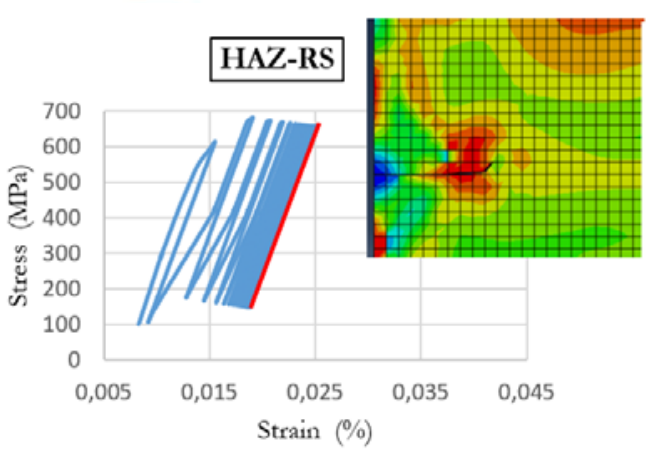

_ Cycle stabilized element 479

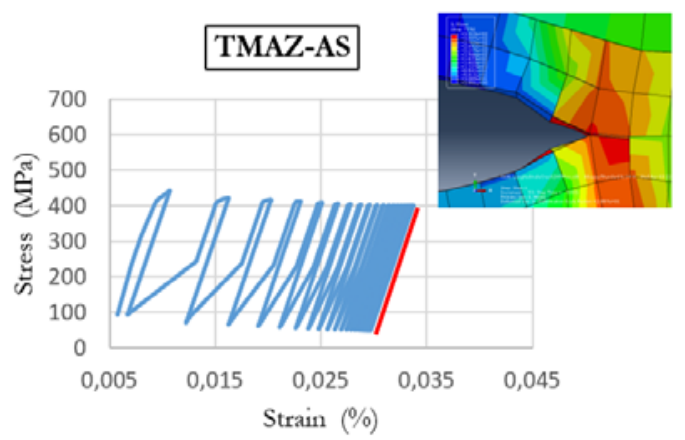

- Cycle stabilized element 429
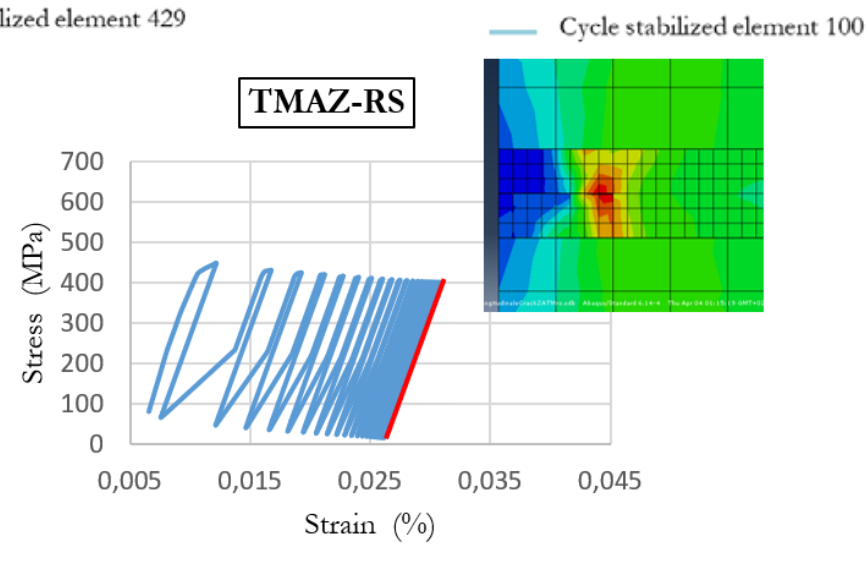

Cycle stabilized element 67

Figure 9: Stress-strain loop in each zone of the welded joint. 
Fig. 8 illustrates the cyclic mechanical behaviour in each of the zones constituting the welded joint in alloy 2024-T351: ZAT (AS-RS), nugget, ZATM (AS-RS). These hysteresis loops recorded at $10^{6}$ cycles; the solution no longer evolves. Convergence is reached and the solution is stable. The points chosen are located after the crack front, the different areas show a ratchet at the start of the test before elastic adaptation. The buckles remain a little closed throughout the test. This is the elastic adaptation phenomenon observed for each zone of the joint. Finally, the difference observed between the asymptotic behaviours of each of the zones is presented in the levels of plastic deformation which appears during the test.

It is noted that the maximum strain is well established in the nugget followed by the ZATM (AS, RS) then those are the ZAT (AS and RS) which are the least deformed.

This last phase represents the place of damage due to the levels of very important deformations. The elastic adaptation is recorded until the end of the test.

Thus, we note that the shape of the cycles is different in each finite element chosen in the structure, but we finally obtain the same adaptation response recorded at the end of the cycle.

By this analysis, we notice that the less deformed zones stabilize more quickly compared to the other zones.

These results showed that the slowest zones to stabilize correspond to the maximum deformation.

\section{CONCLUSION}

he direct cyclic method allowed to determine the local mechanical responses of the different zones of the welded joint by the FSW process of the 2024-T351 aluminum alloy. We have shown that the zones constituting this welded joint exhibit very different behaviors the ones to the others.

The numerical tests in traction-traction $(\mathrm{R}=0.1)$ allowed to highlight the heterogeneities of cyclic mechanical behavior in each of the zones constituting the joint 2024-T351 welded by FSW. The curves of local behavior $\left(\sigma_{22}-\varepsilon_{22}\right)$ in each of the zones made it possible to note that the various zones constituting the joint present very heterogeneous mechanical behaviors, of $0.025 \%$ of deformation in the HAZ and up to $0.038 \%$ of total deformation in the nugget, because of the strong microstructure gradient introduced by the welding process.

For the welded joint in alloy 2024-T351, the deformation field is located in the nugget followed by the ZATM and finally the ZAT.

This study showed the interest of the XFEM method for the simulation of fatigue crack propagation without remeshing or projection of the field.

The coupling of the XFEM with the direct cyclic technique, makes it possible to perform cyclic calculations and obtain the precise response of the studied structure.

\section{REFERENCES}

[1] Ericsson, M., Sandstrom, R. (2002). Influence of welding speed on the fatigue of friction stir welds, and comparison with MIG and TIG. International Journal of Fatigue 25, pp. 1379-1387. DOI: 10.1016/s0142-1123(03)00059-8.

[2] Sangshik, K., Chang, G., Sung, J. (2007). Fatigue crack propagation behavior of friction stir welded 5083-H32 and 6061T651 aluminum alloys, International Journal of Materials Science and Engineering A 478, pp. 56-64.

DOI: https://doi.org/10.1016/j.msea.2007.06.008.

[3] Demmouche, Y. (2012). Study of the fatigue behavior of FSW welded joints for aeronautical applications, Ph.D. Thesis, National School of Arts and Crafts.

[4] Tran, H., Masakazu, O., Kenji, S. (2012). Fatigue crack propagation behavior in friction stir welding of AA6063-T5: Roles of residual stress and microstructure, International Journal of Fatigue 43, pp. 23-29.

DOI: $10.1016 /$ j.ijfatigue.2012.02.003.

[5] Dickerson, T.L., Przydatek, J. (2002). Fatigue of friction stir welds in aluminium alloys that contain root flaws, International Journal of Fatigue, 25, pp. 1399-1409. DOI: 10.1016/S0142-1123(03)00060-4.

[6] Jesper, H., Hattel, M. R. (2014). Modelling residual stresses in friction stir welding of Al alloys-a review of possibilities and future trends, Int J Adv Manuf Technol 76, pp- 1793-1805. DOI: 10.1007/s00170-014-6394-2.

[7] Charitidis, C.A., Dragatogiannis, E.P., Koumoulos, I.A., Kartsonakis (2012). Residual stress and deformation mechanism of friction stir welded aluminum alloys by nanoindentation, International Journal of Materials Science and Engineering A 540, 226. DOI: 10.1016/j.msea.2012.01.129. 
[8] Chahine, E., Laborde, P., Renard, Y. (2006). Crack tip enrichment in the XFEM method using a cut-off function, international journal for numerical methods in engineering, pp- 1-15. DOI: 10.1002/nme.2265.

[9] Živojinović, D., Đurđević, A., Grbović, A., Sedmak, A., Rakin, M. (2014). Numerical modelling of crack propagation in friction stir welded joint made of aluminium alloy, International Journal of Procedia Materials Science 3, pp. $1330-$ 1335. DOI: $10.1016 /$ j.mspro.2014.06.215.

[10] Živojinović, D., Sedmak, A., Grbović, A. (2013). Crack growth analysis in friction stir welded joint zones using extended finit element method, Journal of structural integrity and life, 13, 03.

[11] Elruby, A. Y., Nakhla, S., and Hussein, A. (2018). Automating XFEM Modeling Process for Optimal Failure Predictions, international journal for Mathematical Problems in Engineering, 2018, 1654751. DOI: $10.1155 / 2018 / 1654751$.

[12] Pommier, B. (2003), Determination of the asymptotic response of an anelastic structure subjected to cyclic thermomechanical loading, Ph.D. Thesis, Polytechnic School. DOI: 10.1016/S1631-0721(02)01516-4.

[13] Trollé, B. (2014). Multi-scale simulation of fatigue crack propagation in rails. Ph.D. Thesis, National Institute of Applied Sciences of Lyon.

[14] Elmeguenni, I., Mazari, M. (2019) Numericql investigation on Stress Intensity Fatocr and J Integral in friction stir welded joint throught XFEM method, Frattura ed Integrita Strutturale, 47 (2019) 54-64. DOI: $10.3221 /$ IGF-ESIS.47.05.

[15] Andrijana, D., Danijila, Z., Aleksandar, G., Aleksandar, S., Marko, R., Horia, D., Snezana, K., (2015). Numerical simulation of crack propagation in friction stir welded joint made of Al 2024-T351 alloy, Int. J. of Engineering Failure Analysis, 58, pp. 477-484.

[16] Herbland, T. (2009) AN elastoplastic correction method for the fatigue calculation of the stress concentration zones under non-proportional multiaxial cyclic loading, Ph.D. Thesis, Mines school of Paris.

[17] Casey, L., Richardson, J., Hegemann, E., (2002). An XFEM method for modelling geometrically elaborate crack propagation in brittle materials, international journal for numerical methods in engineering, DOI: 10.1002/nme.321.

[18] Benhaddou, M., Ghammouri, M., Latrache, F., Hammouch, Z. Study of cleavage in a rectangular plate by the XFEM method and the integral contour J method, International journal of Materials Today: Proceedings. DOI: $10.1016 /$ j.matpr.2020.03.256.

[19] Lok singh, K., Keswani. K, Vaggar. M, (2014). Crack growth simulation of stiffened fuselage panels using XFEM techniques, Indian journal of engineering of materials sciences, 21, pp.418-428.

[20] Bjr Zagane, M., El Sallah Benbarek, S., Benouis. A. (2017). Numerical Simulation of The Femur Fracture With and Without Prosthesis Under Static Loading Using Extended Finite Element Method (X-FEM), Journal of Mechanical Engineering, 14(1), 97-112.

[21] Golestaneh, A. F., Aidy A., Shaw Voon, W. (2008). Simulation of fatigue crack growth in friction stir welded joints in 2024-t351 al alloy, Suranaree J. Sci. Technol. 15(4).

[22] Liu, G., Hu, Y., Li, Q. and Zuo, Z. (2013). XFEM for Thermal Crack of Massive Concrete, (2013), Mathematical Problems in Engineering, 343842, DOI: 10.1155/2013/343842.

[23] Cavaliere. P. (2013). Friction stir welding of Al alloys: analysis of processing parameters affecting mechanical behavior, 2nd International Through-life Engineering Services Conference, Elsevier.

[24] Genevois, C. (2004). Genesis of microstructures during friction stir welding of aluminium alloy of the series $2000 \&$ 5000 and resulting mechanical behavior, Ph.D. Thesis, Polytechnic national institute of Grenoble. 